\title{
revista.tradumàtica
}

16

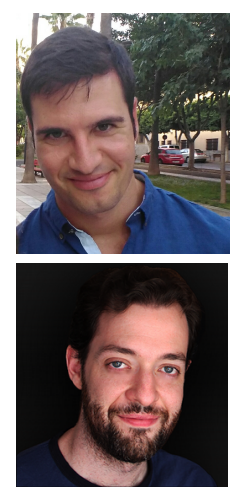

\section{The ins and outs of the video game localization process for mobile devices}

Pablo Muñoz Sánchez

Universitat Autònoma de Barcelona,

Rafael López Sánchez

Audiovisual translator and localizer

\begin{abstract}
This article aims to provide an overview of the video game localization process for mobile devices. It describes, step by step, the different stages and parties involved throughout the process; with a special emphasis on the translation, review, and testing stages.
\end{abstract}

Keywords: video game localization, game translation, mobile devices, smartphones, tablets, game systems, Android, iOS

\section{RESUM}

L'objectiu d'aquest article és el d'oferir una panoràmica del procés de localització de videojocs per a dispositius mòbils i consoles. Descriu, pas per pas, les diverses fases i parts del procés, amb un èmfasi especial en la localització, la revisió i la verificació. Per últim, analitza els reptes que han d'afrontar els professionals de la indústria de la localització, amb referències a exemples pràctics i casos reals.

Paraules clau: localització de videojocs, traducció de jocs, dispositius mòbils, telèfons intel-ligents, tauletes, consoles de jocs, consoles híbrides de videojocs, android, iOS

\section{RESUMEN}

El objetivo de este artículo es el de ofrecer una panorámica del proceso de localización de videojuegos para dispositivos móviles y consolas. Describe, paso a paso, las diferentes fases y partes del proceso, haciendo un especial hincapié en la localización, la revisión y el testeo. Por último, analiza los retos a los que se enfrentan los profesionales de la industria de la localización, recorriendo ejemplos prácticos y casos reales.

Palabras clave: localización de videojuegos, traducción de juegos, dispositivos móviles, teléfonos inteligentes, tabletas, consolas de juegos, consolas híbridas de videojuegos, android, iOS

\section{Introduction}

Video game localization and mobile app localization are amid an era of glory. More video games than ever are being consumed, and the largest consumer platform is, in fact, mobile devices. No wonder, the mobile video game Pokémon GO (2016) achieved a revenue of 470 million dollars within only 80 days of its release, even though it was not a simultaneous release in all regions (Newzoo, 2016). Moreover, it is estimated that in 2016 mobile video games will raise approximately $\$ 36.9$ billion globally (Newzoo, 2016). Naturally, one of the keys to success is localizing video games for mobile devices. In 2014 alone, mobile video games collected $\$ 3.2$ billion in Western Europe (Pearce, 2014). 
However, even though in recent years there have been many publications regarding video game localization, among which Chandler and O'Malley (2011), O'Hagan and Mangiron (2013), and Bernal Merino (2015) stand out, little attention has been dedicated to the specificities of video game localization for mobile devices, except for the publication by Torres Molina (2007). Therefore, this article intends to gather the most significant particularities of the localization process for these types of games.

\section{Internationalization}

Without a doubt, the internationalization stage is fundamental to minimize the number of problems when translating, or even when implementing the text strings. Android, iOS and Windows 10 Mobile have integrated internationalization. Therefore, if apps are developed following the standard guidelines of such operating systems, translators and developers barely have to worry about the space available on screen, as studied in Muñoz Sánchez (2016).

Unfortunately, this favorable native internationalization cannot be used with video games, as they each have their own interface that does not follow a specific design pattern, so the developer must make an additional effort to achieve a good localization. Thus, the development team must keep in mind the following good practices:

- Separation of the translatable text from the source code: It is recommended to include all the text strings in a separate text file to facilitate its translation and implementation, so that only the development team deals with the source code. If there is graphic text, it must also be separated from the code to facilitate editing and implementation.

- Selection of appropriate fonts and coding for different languages: There is nothing worse than discovering, after implementing the text, that the font does not show some special characters, such as the Spanish ' $\tilde{n}$ '. Therefore, choosing from the beginning a font that allows all possible characters, even if localizing to a specific language is still not being considered, will avoid future problems. It is also key to consider character encoding, as certain coding systems are not compatible with certain languages. It is currently recommended to use encoding such as Unicode, which allows more than fifty-thousand symbols compatible with most languages, or to resort to ISO character sets.

- Interface design adaptable to the text shown or with plenty of space: Resources used in many video games include speech bubbles, text boxes, menus, etc. The best solution in these cases is that bubbles or windows adapt to the content as in standard applications (Muñoz Sánchez, 2016), rather than setting a maximum character or pixel number per line and a maximum number of lines per bubble. If this were not possible, these elements should at least be designed with plenty of extra space. In addition, it is useful to have a variable-width font, i.e. a font in which each character has its own size, so for example the ' $i$ ' uses less space than the ' $w$ ' (unlike a fixedwidth font like Courier New). This would make life simpler for translators, as they could make the most of their creativity without too many space limitations.

- Use of special tags for gender, sex or number: Although sometimes neutral expressions can be used (such as in the Spanish example, "iQué atractivo tienes!" instead of " $Q$ Qué atractivo eres!" ["You have great appeal!" as opposed to "You are very attractive!"], the latter of which requires the marker for masculine or feminine in Spanish), it is best to add tags that allow changing the message in real time, depending on if the interlocutor is a man or a woman. An example of this in gender marked languages would be: Eres muy <gender $><$ masculine $>$ guapo $<$ feminine $>$ guapa $<$ end_gender> (an example in English would be: You are very < gender $><$ masculine $>$ hand- 
some<feminine $>$ beautiful<end_gender>.)

There are also computer-aided translation tools (CAT) which allow adding context and additional information to the strings so that translators can solve these problems more easily.

Figures 1 and 2 below show how video game interface localization has evolved since Super Nintendo until today. While the original Chrono Trigger from 1995 hardly had enough space for the battle menus, the iOS and Android versions have battle menus with enough space for the text.

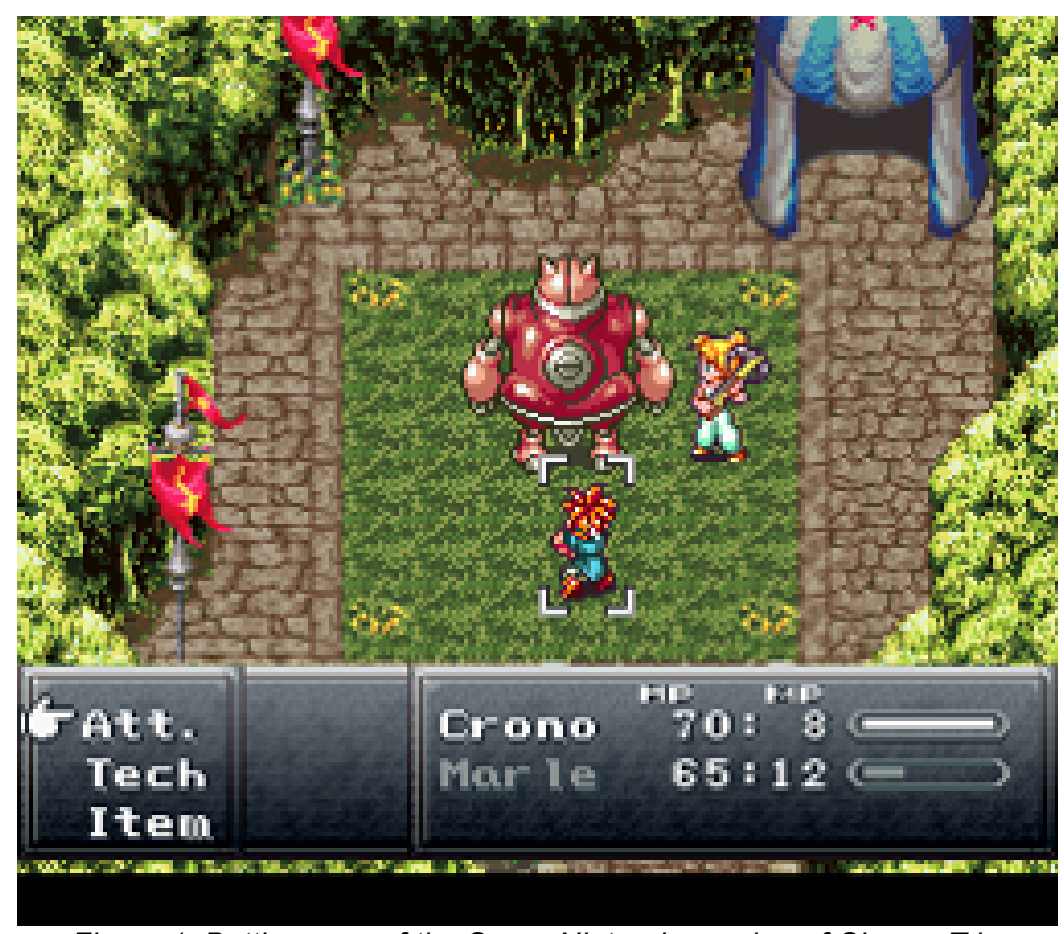

Figure 1. Battle menu of the Super Nintendo version of Chrono Trigger (C 1995, 2008, 2011 SQUARE ENIX CO., LTD) 


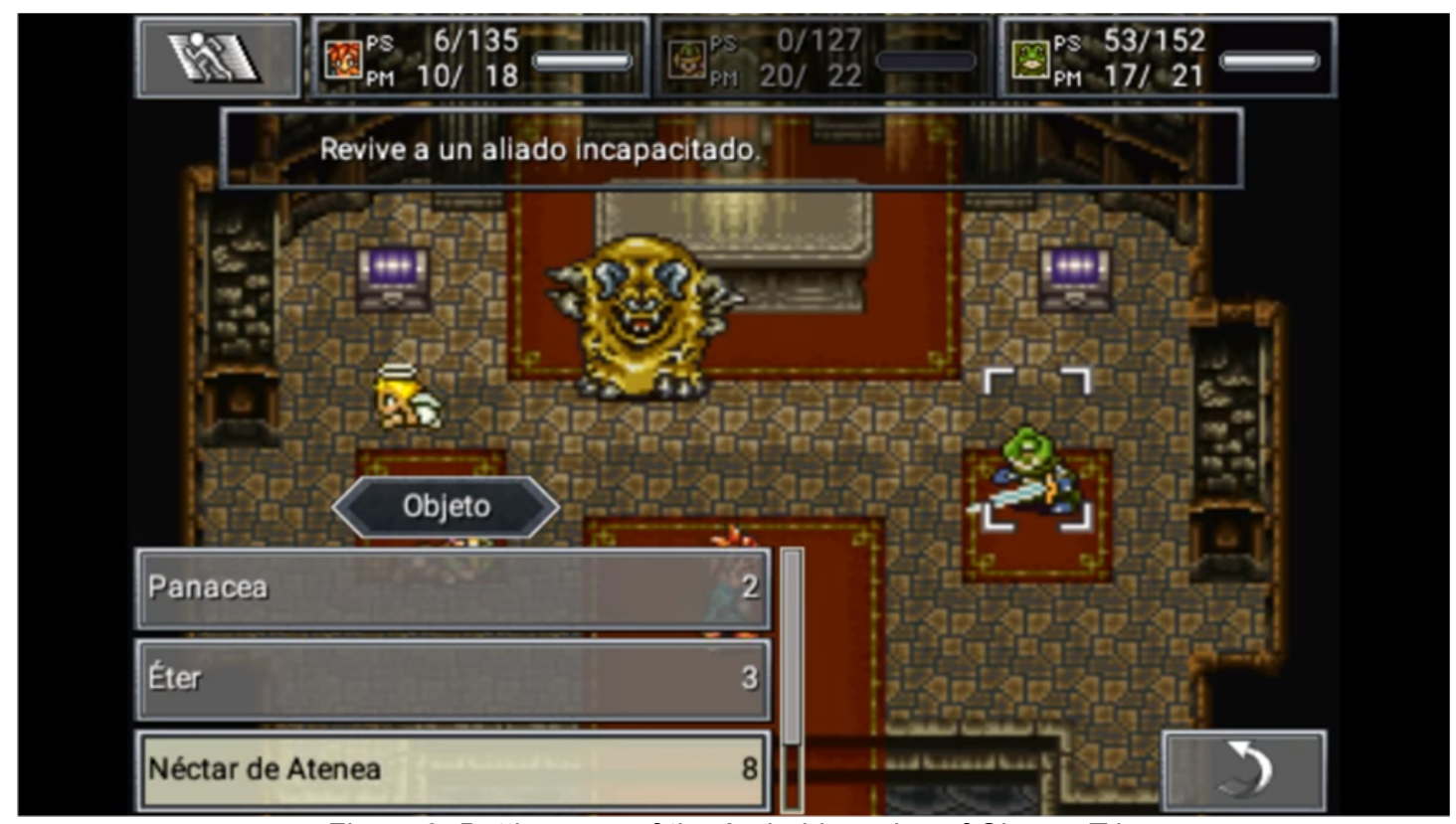

Figure 2. Battle menu of the Android version of Chrono Trigger

(C) 1995, 2008, 2011 SQUARE ENIX CO., LTD)

\section{Localization and translation}

One of the features of video games is their language, which is generally very creative. Therefore, the translator must be prepared to tackle the plays on words as well as dialogs with different tones, depending on the character. Naturally, each game has its own features and we could dedicate a whole paper to the endless translation problems; thus, this section will be focused on describing different elements that must be translated in a video game.

\subsection{User Interface (UI)}

The user interface, commonly known as UI, allows users to interact with the different elements in the video game. It has several elements, namely menus, buttons and system messages. The language used here is influenced by other specialized areas, such as software localization and even legal translation, as shown in Figure 3. 


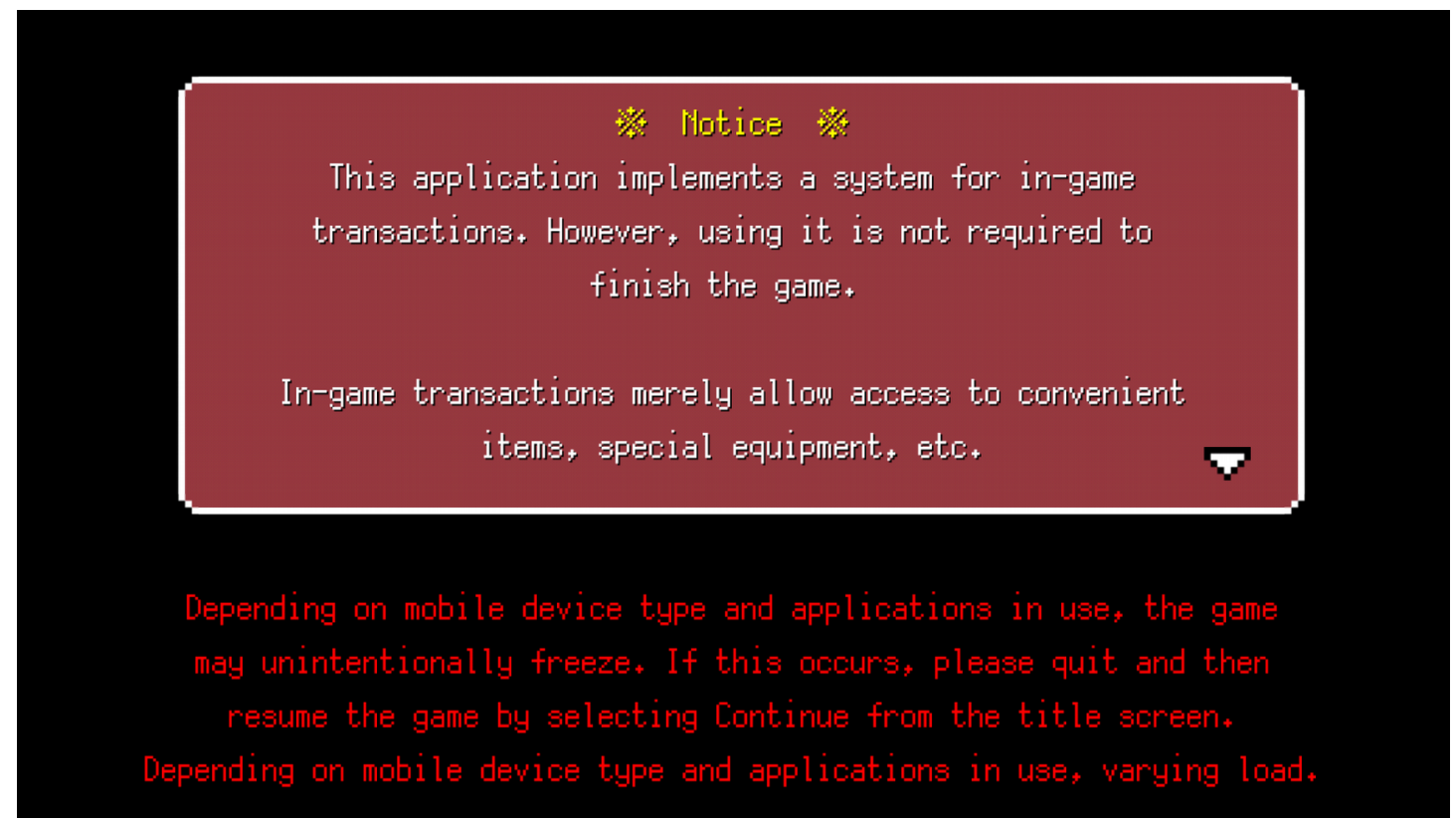

Figure 3. Text with a more technical/legal tone in the Android version of Dragon Sinker (C) 2015 KEMCO/EXE-CREATE)

Even then, it is necessary to have video game knowledge to know, for example, that "BGM" and "SE" are referencing BackGround Music and Sound Effects respectively, as shown in Figures 4 and 5.

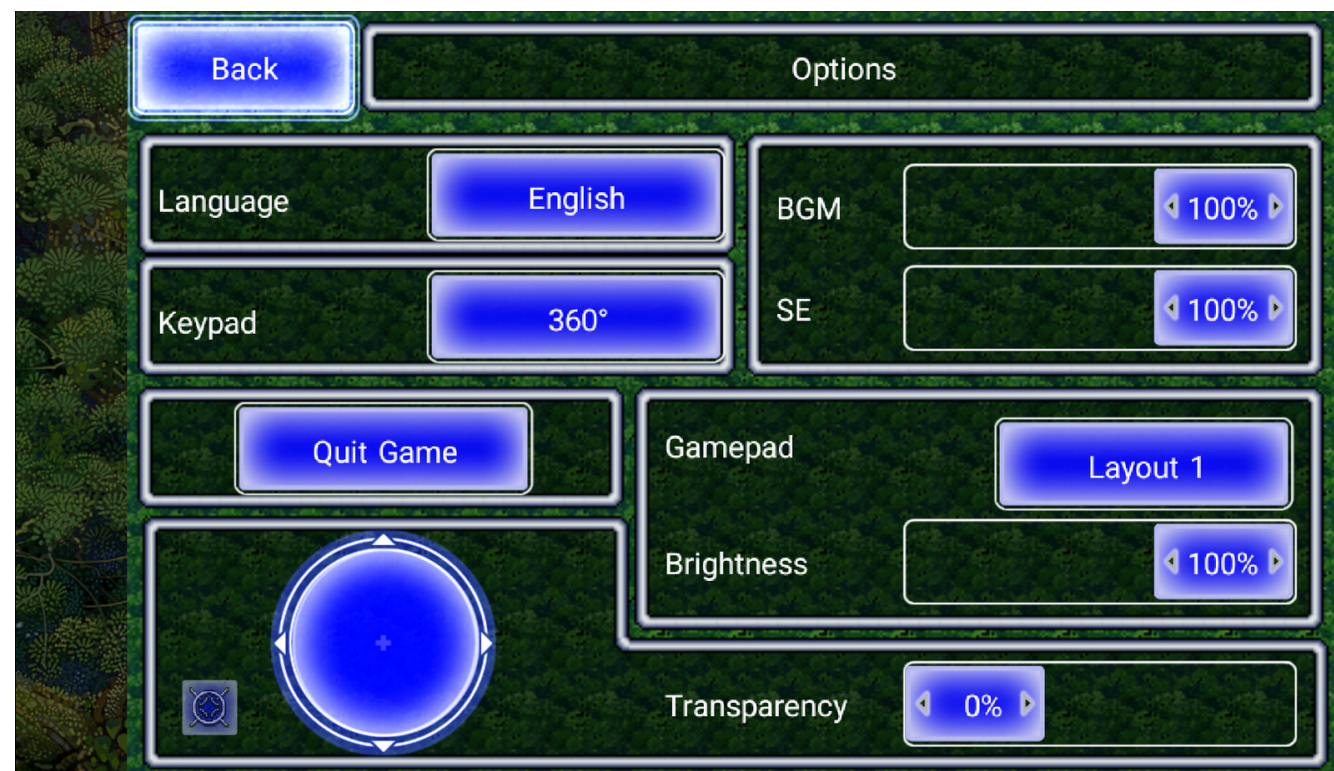

Change the game's language.

Figure 4. English options menu of the Android version of Secret of Mana (C 1993, 2010 SQUARE ENIX CO., LTD) 


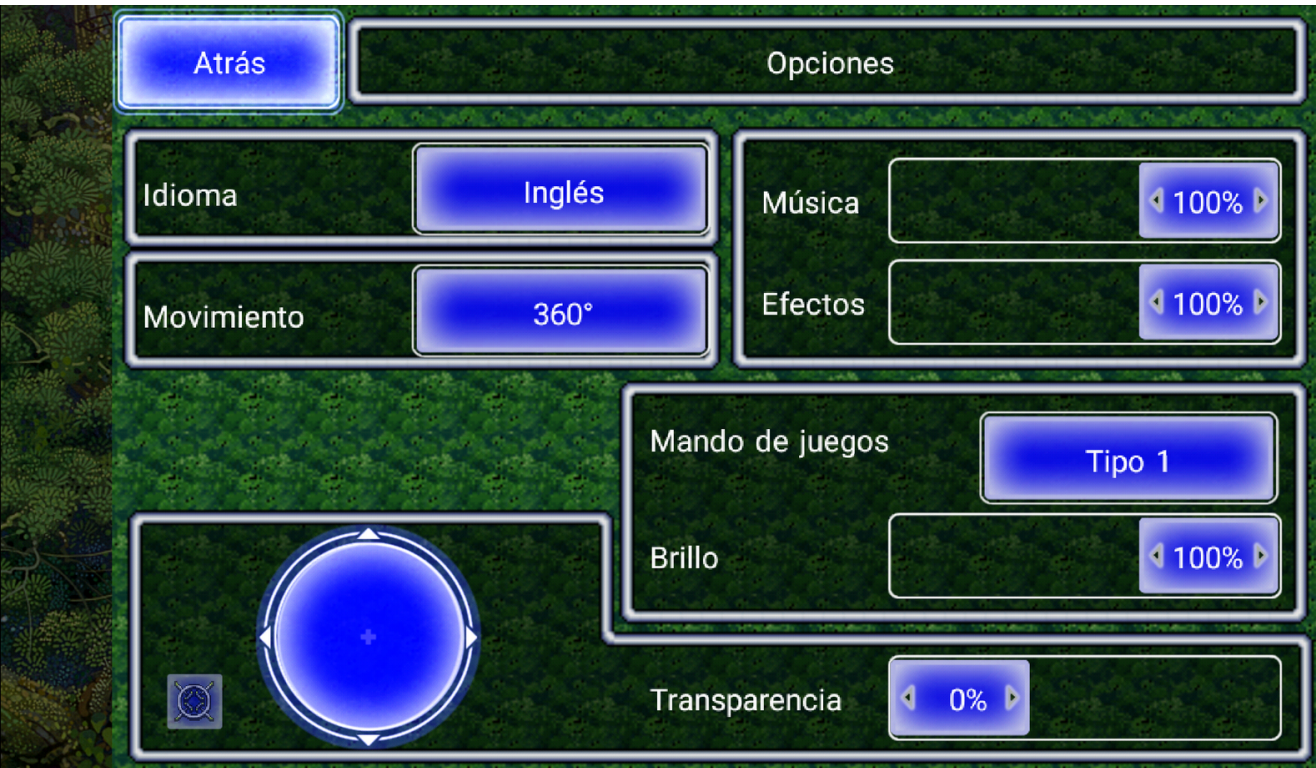

Cambia el idioma del juego.

Figure 5. Spanish options menu of the Android version of Secret of Mana (C 1993, 2010 SQUARE ENIX CO., LTD)

Obviously, beyond the typical system messages, the UI of a mobile video game has specific specialized language elements that are useful to know, such as the character attribute names, as shown in Figures 6 and 7 below.

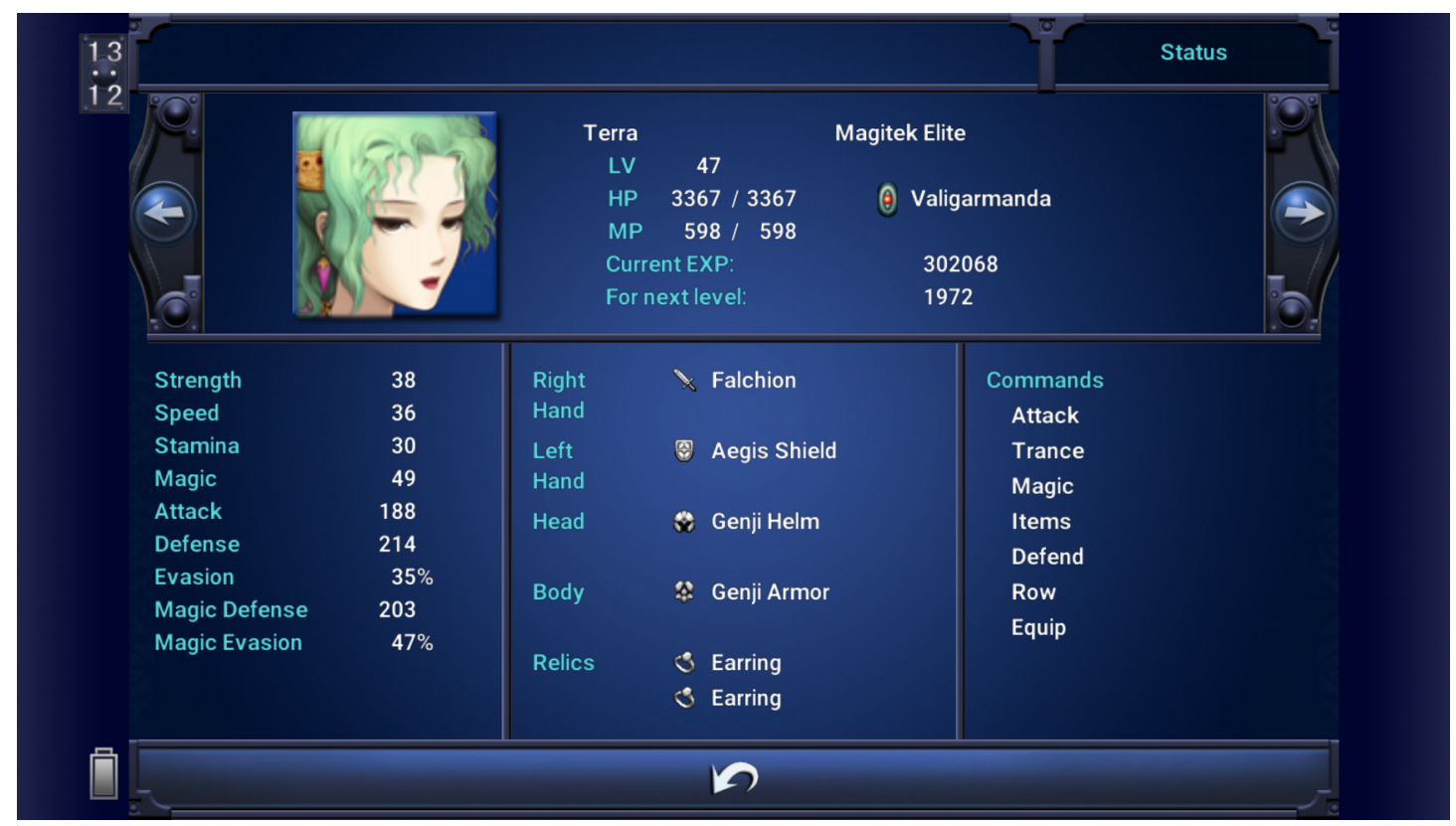

Figure 6. English status menu of the Android version of Final Fantasy VI (C 1994, 2006, 2014 SQUARE ENIX CO., LTD) 


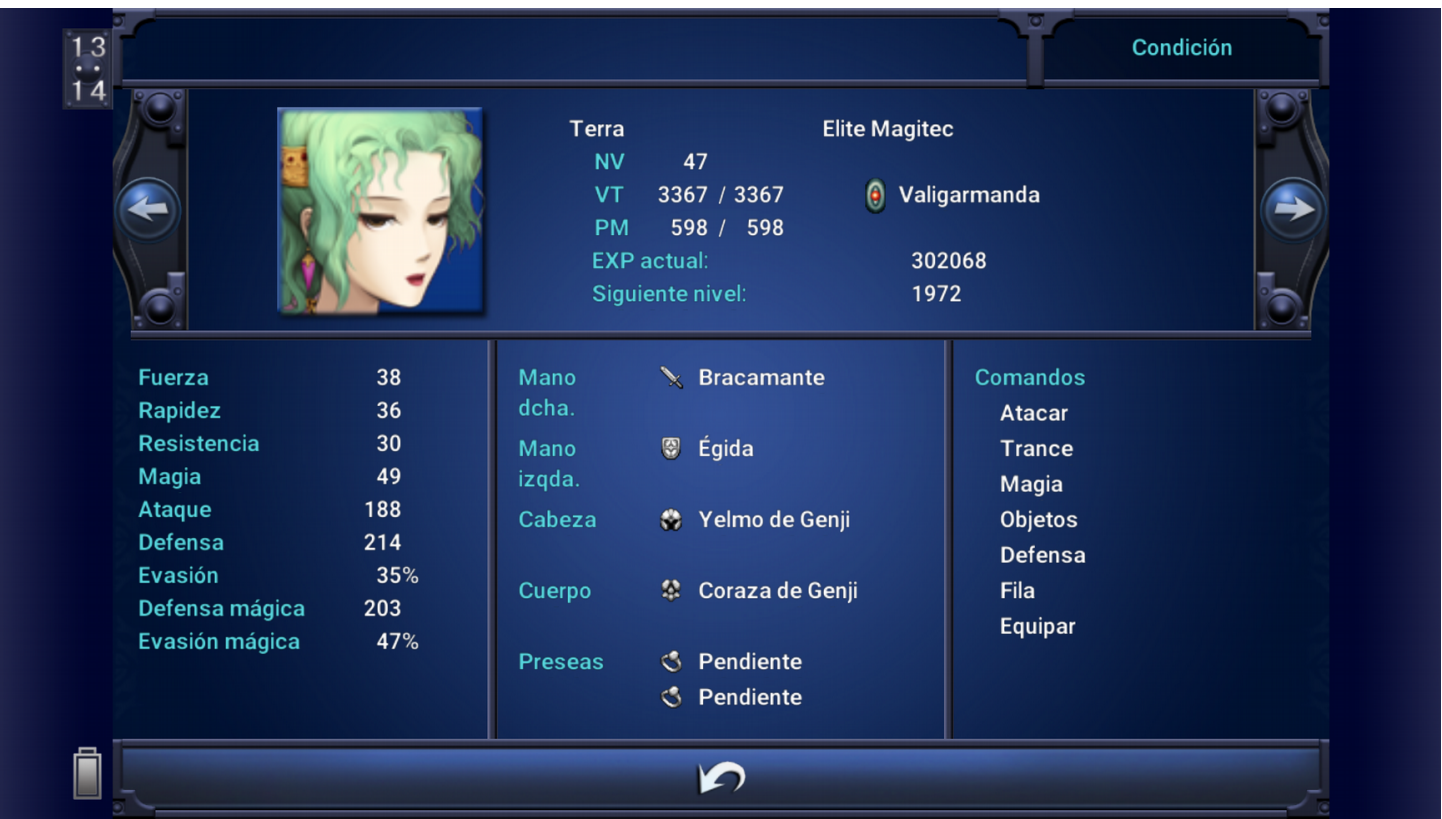

Figure 7. Spanish status menu of the Android version of Final Fantasy VI

(C 1994, 2006, 2014 SQUARE ENIX CO., LTD)

\subsection{Conversations}

Mobile video games often do not have audio dialogs, as their size in memory would increase greatly (let's not forget space is usually limited in these devices). Therefore, most conversations in video games happen through text dialogs. There is no doubt that this is where the translator's creativity shines, as the language can range from epic (Figure 8 ) to poetic and funny (Figure 9) depending on the character depiction.

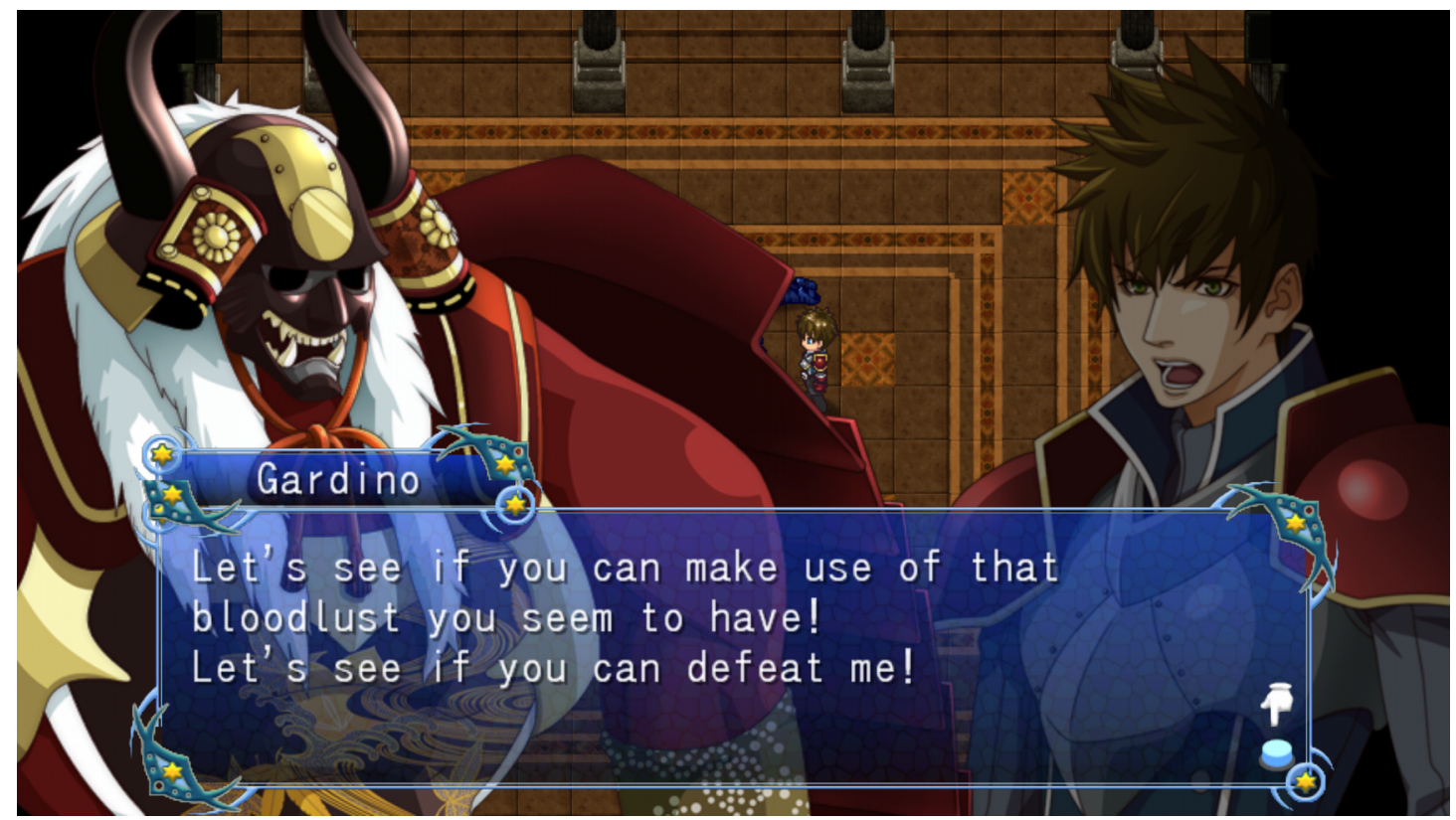

Figure 8. Epic dialog of the Android version of Symphony of the Origin

(C 2012/2014 KEMCO/WorldWideSoftware) 


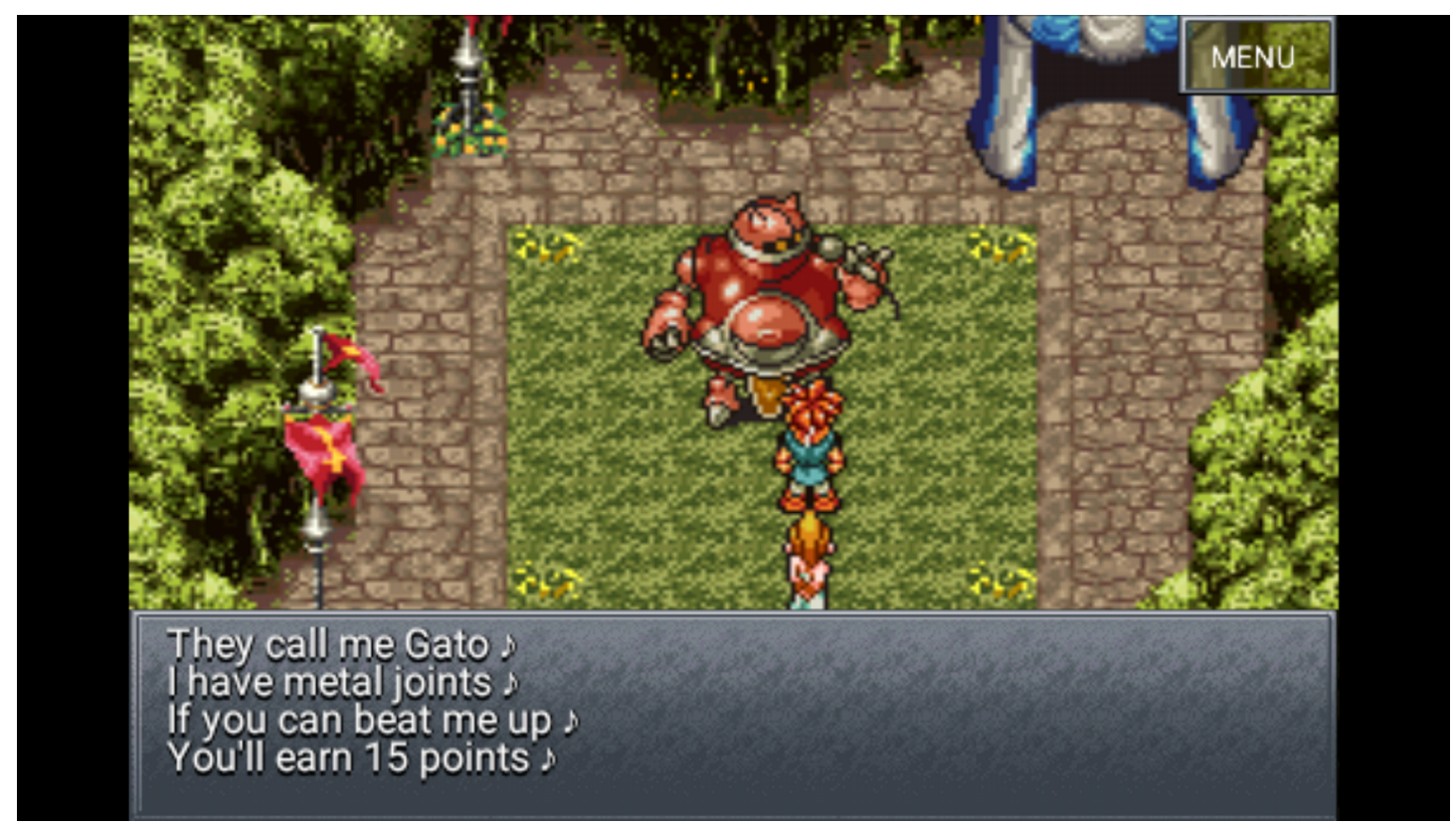

Figure 9. Poetic and funny dialog of the Android version of Chrono Trigger (C 1995, 2008, 2011 SQUARE ENIX CO., LTD)

\subsection{App store descriptions}

The texts in the app stores (mainly Google Play for Android, App Store for iOS and Windows Store for Windows 10/Windows 10 Mobile) are essential for the success of the app. Not only do they describe what to expect from the video game, but its content also works as keywords when searching one of the app stores. For this reason, many video games do not have a localized UI, but they do have a translated description. A translated description with well-selected keywords can increase the number of downloads substantially, as proven in the study by Janner (2013).

Due to this, just as a website uses Search Engine Optimization techniques (SEO), currently many developers use App Store Optimization practices (ASO). Thus, it is not surprising that the assignment instructions require researching which keywords are the most common for a game of a specific genre to use them as much as possible. Additionally, because the title and short description of an app or game are the elements with most weight to appear in searches, it is not surprising that many games include keywords directly in these fields (such as "RPG" or "free"; see Figure 10). 


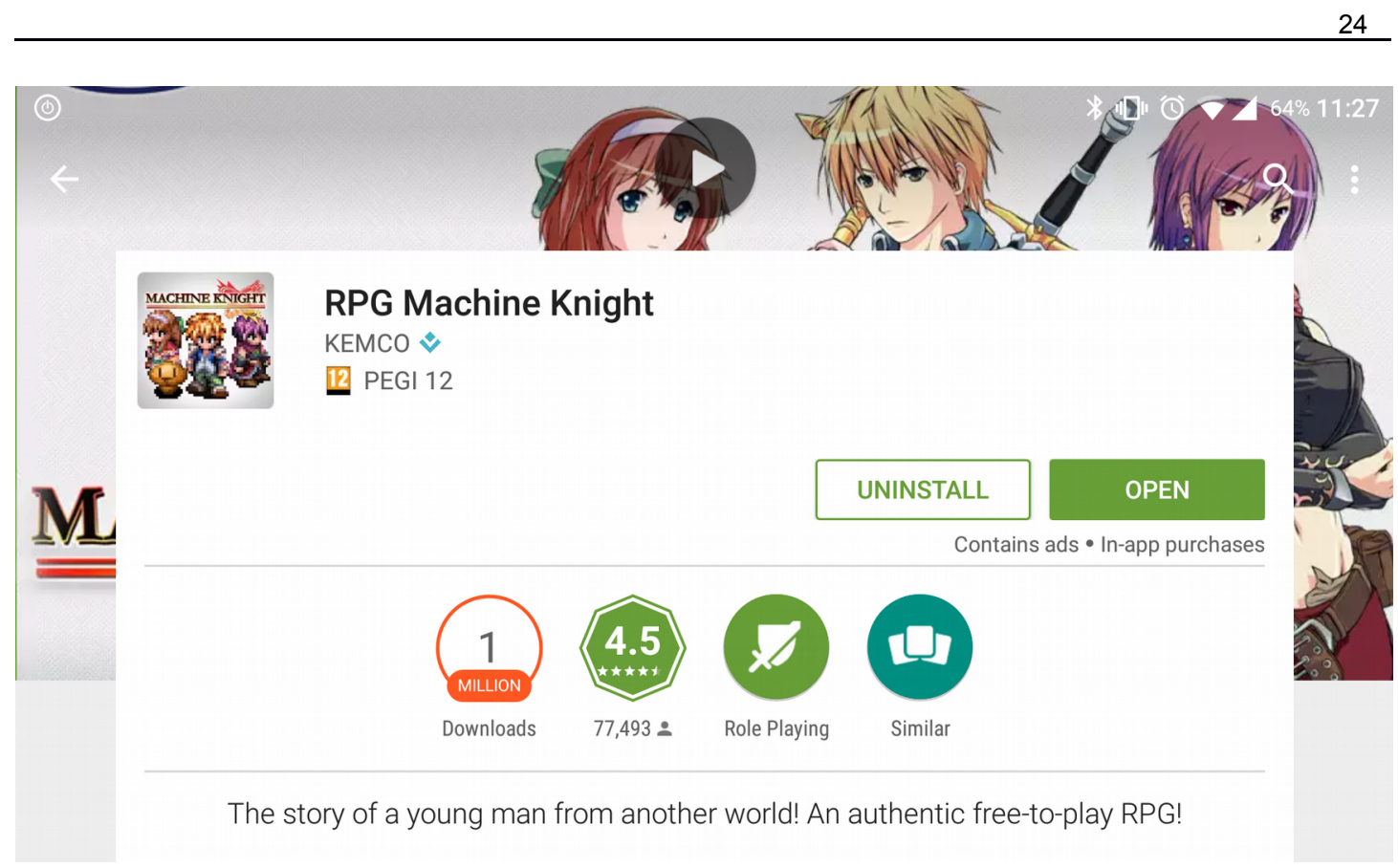

Figure 10. Title and short description on Google Play of Machine Knight

(C) 2011-2012 KEMCO/Hit-Point)

It is also important to pay attention to the images that support the game description, as not localizing them or partially localizing them could create the impression that the game is not localized. For example, although the video game Clash of Clans is very well known and its localization is very carefully done in general, one of the images on their Google Play Store could give the impression that it is not translated, as the interface is in English while the top banner is in Spanish, as shown in Figure 11. 


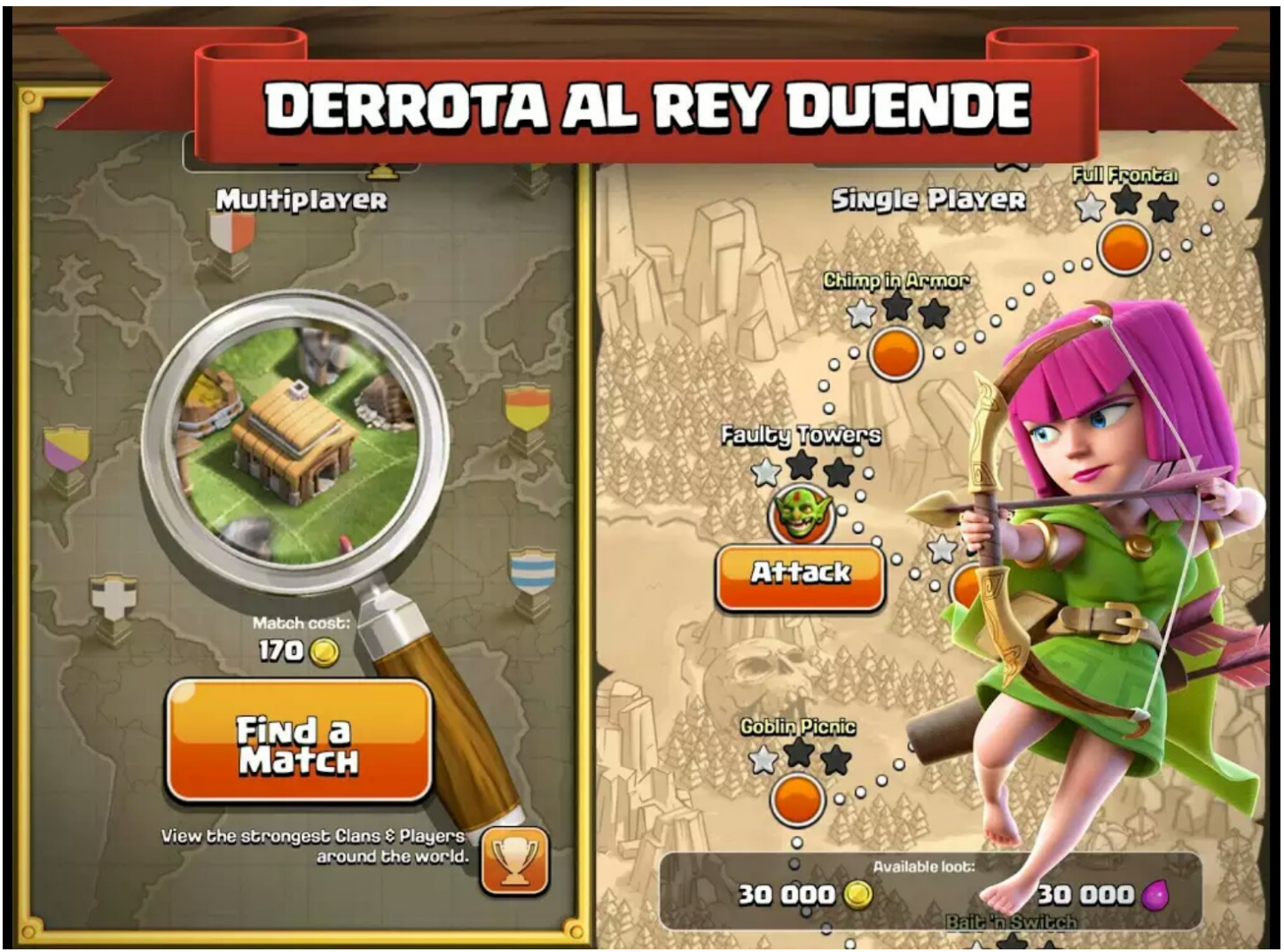

Figure 11. English interface with a banner in Spanish in the Google Play Store image of Clash of Clans (@ 2012 Supercell)

\subsection{Ads}

Lastly, another common element that requires translation is the advertisements that try to promote the installation of the game. In general, although there may be all types of ads, included those in-game, the two most common ad formats are Google AdWords and social media ads.

\subsubsection{Google AdWords ads}

The ads that appear on the Google search engine and on the pages that use the Google search network are known as AdWords. They are widely used due to their effectiveness and popularity. As in all good ads, it is common to find a call-to-action (CTA), that is, actions that the user must do, such as "Download it now!"

Regarding their translation, limitations are normally a problem. Titles have a maximum of 25 characters and the two description lines have a maximum of 35 characters each. It is therefore always a great challenge to translate each message creatively and maintain attractiveness for the user. There are also expanded ads, with more available space, but in general the ones that get translated are the simple ads with 25/35 characters. Figure 12 shows the typical aspect of an AdWords ad. 


\begin{tabular}{|l|}
\hline Clash Royale \\
clashroyale.com/download \\
Epic and ridiculous duels! \\
Download Free \\
\hline
\end{tabular}

Figure 12. Google AdWords ad

\subsubsection{Social media ads}

Due to the popularity of social media, companies also invest many resources in promoting their apps and games on social media such as Facebook, Twitter or Instagram. From a localization point of view, the translator must be very creative to transcreate a message that attracts the player's attention. To do so, again, the translator must keep in mind the space available for each ad. Figure 13 below, extracted from D'Angelo (2015), shows how creative some of these ads are.

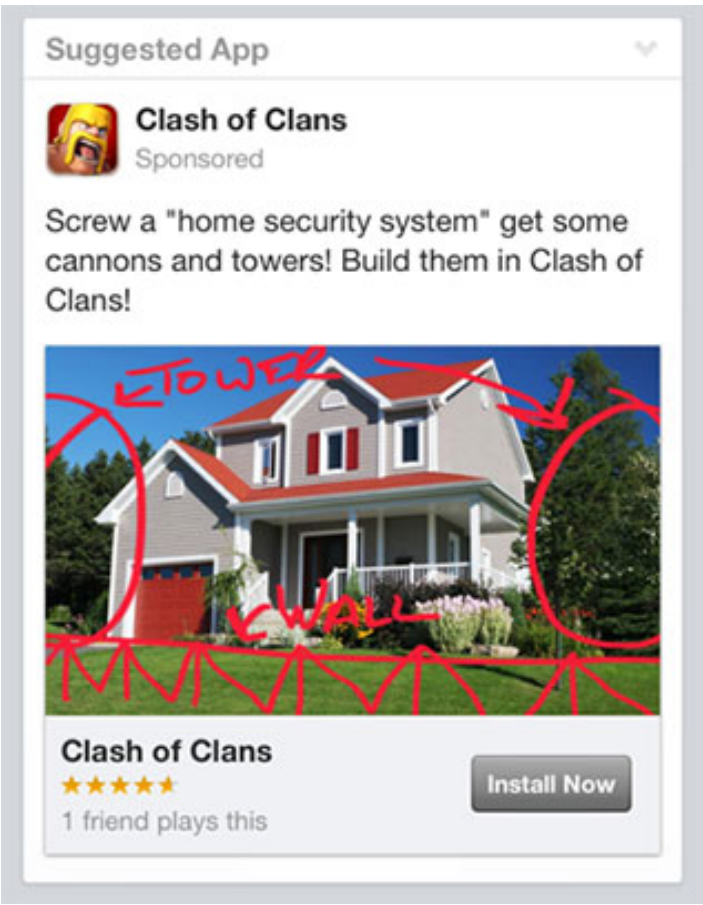

\section{Suggested App

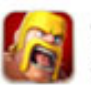 \\ Clash of Clans \\ Sponsored}

One drives kids, the other drives the HAMMER! Attack NOW in the free, Clash of Clans!

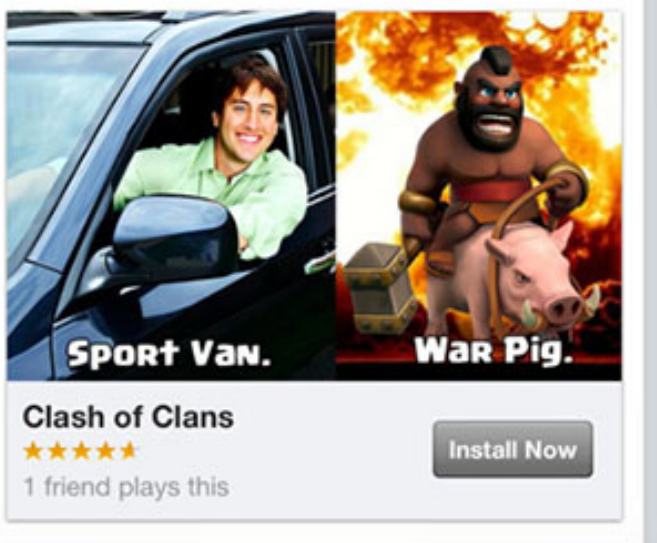

Figure 13. Facebook ads for Clash of Clans (@ 2012 Supercell)

\section{Review}

Quality in translation has always been a very subjective concept, as it is a slippery slope. In fact, the regulations that standardize translation quality, such as standard UNE-EN-15038 for Translation Services, have changed greatly in the last years. Translation quality requires standardization and the use of unified criteria to overcome language's arbitrariness, as explained by Parra (2011) and Arevalillo (2015). Indeed, unified criteria as those established by the UNE-EN15038 are the guidelines for many companies and freelancers in the professional translation market to measure the quality of its translations. Thus, reviewers working in such companies must keep them in mind, including those localization specialists and professionals in the video game industry. 


\subsection{Main review methods}

There are reference manuals, such as Manual de revisión de la Comisión Europea (written originally in Spanish, European Commission Review Manual, 2010) and Revising and editing for translators by Brian Mossop (2014), that recommend several methods of revising and editing translations. Among them, in this article we will highlight the following:

- Self-revising: In this case, the translator reviews his own translation. Generally, it is recommended that the review task is done by another specialist (and it is normally the case), but in practice it normally happens that many translators also review their own texts. In any case, and although it might seem like a truism, we would like to remind the reader of the importance of the translator's reviewing their own text before delivering it for review.

- Comparative check: The comparative review is currently the most recommended technique. As the name indicates, it consists in comparing the original text to the translation to detect and correct the possible errors. In this case, the reviewer is the one who makes the appropriate decisions and who has the last say about the translated text. There are several approaches. In this article, we will highlight the ones we consider more widespread:

- One of them would be the thorough review method proposed in the European Commission Review Manual (some experts, such as Mossop, call this technique editing), in which the reviewer reads the translation and the original text one sentence at a time and introduces their own changes.

- Another option recommended by the manual is the cross-reading technique, in which the reviewer reads the translation directly and only checks the original text when s/he suspects that there might be an error in the target text. As Mossop (2014) explains, the review does not only consist in correcting errors, but also in knowing how to detect them. Consequently, this technique is usually more productive than the former, although it requires that the professionals putting it into practice have a vast experience so that they do not miss any details.

- Change validation: In this technique, the reviewer sends the translator a suggestion report, and therefore the translator has the last say about the changes in the text before delivery. As Muñoz Sánchez (2010) indicates, this technique is slower than the others, as the reviewer must send the report to the translator and justify all the changes suggested, instead of making them directly following their own criteria. The main advantage offered by this practice is that the translator has the final say and that they can judge the appropriateness of the suggested changes.

\subsection{Review parameters of video game localization for mobile devices}

In his seminal work, Mossop (2014) classifies the possible problems or errors that a reviewer must find in the following groups:

- Problems of meaning transfer: The target text always must accurately reflect all the meaning of the original text (completeness). The reviewer, therefore, must ensure that there are no errors when transferring the meaning during the translation process.

- Problems of content: The translated text must follow the logical sequence and present the same arguments (facts) as the original text.

- Problems of language and style: Smoothness, idioms, register, terminology, sublanguage, tailoring, violation of spelling and grammar rules, among others. 
- Problems of physical presentation: This group includes all the errors related to text presentation, such as layout, structure, or typography, among others. In video game localization, there are often many presentation errors caused by the absence of visual context, as translators are not able to see the game on screen as they translate.

In addition to paying attention to the common errors presented above, the video game localization specialist reviewer must detect other problems of a technical nature, which we will call "localization issues". In video game localization, there are frequently requirements and parameters to comply with. These can be from limitations set in the text during the development process to requirements set by the client. Among them, we would highlight the following:

- Character limitation: Translators must often make sure they do not exceed a certain number of characters in the translated strings. The reviewer must ensure that this limitation is complied with strictly.

- Segmentation: Due to the reduced size of the mobile device screens, sometimes line breaks must be added in the correct places to guarantee the correct text organization. The segmentation can be generated in different ways, e.g. by adding special codes (such as <br> or $\mathrm{ln}$ ) or a normal carriage return, to mention two common methods. In any case, the reviewer must ensure that the text segmentation is done adequately.

- Use of tags: As we have seen above, tags are often used to mark the texts. The reviewer must make sure that the tags have been interpreted correctly and that the texts comply with the requirements of the tags (e. g., "female" to indicate that a specific string refers to a female character or that must be translated in the feminine gender).

- Use of special codes: Texts normally incorporate special codes to format them or to add graphic elements (e. g., buttons). The reviewer must make sure that these codes have been applied correctly to the translated text.

- Use of variables and special characters: Variables are calls that cause a specific text to appear (it can be as small as a number, up to one segment or paragraph). The reviewer must make sure that the variables have been placed in the correct location so that the meaning and style of the text are not altered.

- Help and additional content: It is common for clients and companies to ask translators not only to translate the video game content, but also the help text, marketing and promotion texts, warnings, regulations, links, and other content frequently published on websites to make apps lighter. We consider this kind of issue as a technical problem not because of the content itself, but because of the file formats used by the clients, as they usually need to translate technical files (e. g., HTML or XML files).

Figure 14 shows some errors indicated in red by a reviewer. The figure shows the ID, the character limitation and the character count, as well as common resources to avoid exceeding limitations such as variables and abbreviations. 


\begin{tabular}{|c|c|c|c|c|}
\hline 4 & E & $\mathrm{F}$ & G & H \\
\hline 1 & ID & Character Limit & Spanish & Character Count \\
\hline 2 & 1 & 35 & londres esta a punto de explotar & 32 \\
\hline 3 & 2 & 17 & Tiempo a batir: \%s & 18 \\
\hline 4 & 3 & 17 & Mejor tiempo: \%s & 16 \\
\hline 5 & 4 & 72 & ¿Han superado tus mejores partidas? iComprúebalo con el Sargento Aziz! & 70 \\
\hline 6 & 5 & 60 & ¡Comprueba quiénes de tus amigos están jugando a Tempo! & 55 \\
\hline 7 & 6 & 60 & iTienes \%s $€$ disponibles para gastar en Tempo! & 46 \\
\hline 8 & 7 & 72 & iSe agota el tiempo para parar las bombas de Moloch y salvar Londres! & 69 \\
\hline 9 & 8 & 72 & ¡Todavia quedan $\{\% \mathrm{~s}\}$ medallas de oro por conseguir en Tempo! & 60 \\
\hline 10 & 9 & 72 & Los miembros de tu UAT aún están retenidos como rehenes. iRescátalos! & 69 \\
\hline
\end{tabular}

Figure 14. Screenshot of errors on an Excel spreadsheet with texts of a game for mobile devices (C) 2015 WarChest Limited)

\section{Linguistic quality control (testing)}

Testing or linguistic quality control (also known as Quality Assessment/Assurance [QA] and Quality Control/Check [QC]) is the stage of a video game localization process consisting in verifying how the translated texts look on the screen to detect possible problems. Professionals such as Barceló (2011) and Muñoz Sánchez (2011) agree that the testing stage is probably the most important one of the localization process, as it is during this stage that the complete game can be seen on screen just as the final user would play it.

Figure 15 shows two errors that were not fixed during the review stage and appeared on screen in the game's beta version ("londres" in lower case and "esta" instead of "está"). Fortunately, the tester spotted them and reported them on time.

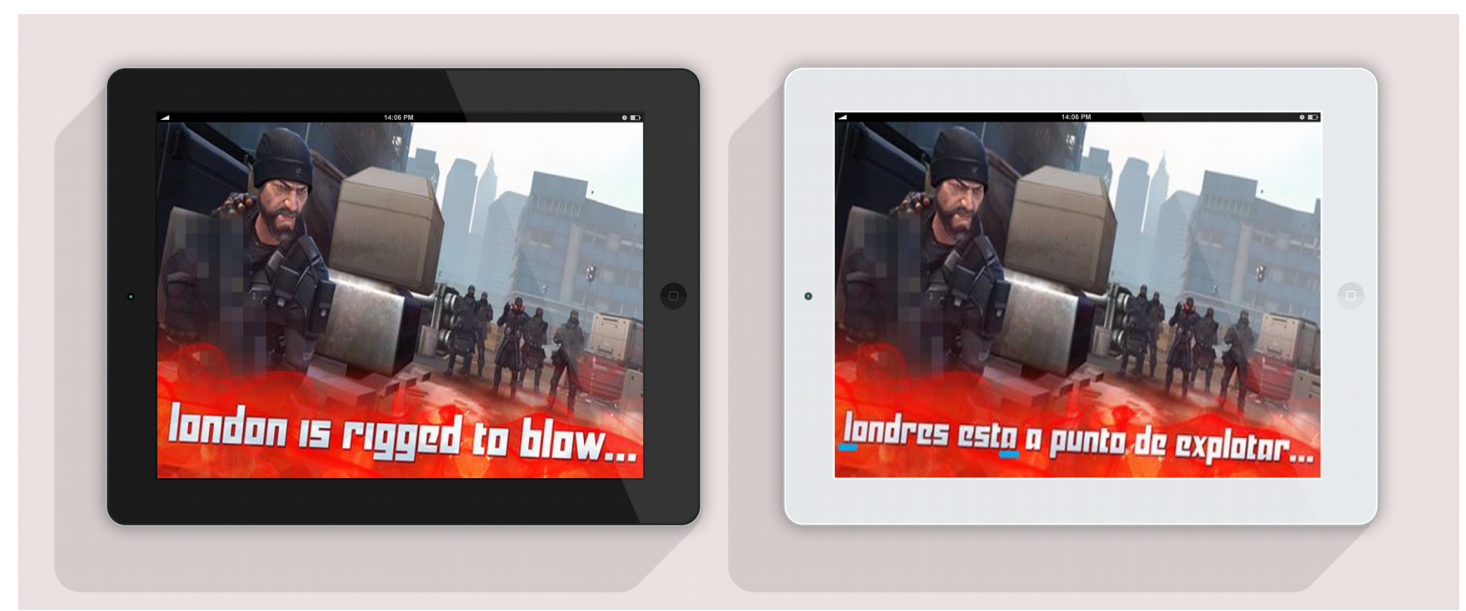

Figure 15. Screenshot of errors found on screen during the testing stage (@ 2015 WarChest Limited)

The testing process on mobile devices is not too different from that on other devices, such as computers or game consoles. However, as explained below, there are certain technical specificities mainly related to the use of tools and file formats. Moreover, the use of mobile devices means testing with a way of interacting that is different than the traditional one, as the most common scenario is the user interacting with the game through a small touchscreen. However, as can be seen in Figure 16, the use of controllers, pads or even compatible virtual reality glasses is becoming more frequent and it must be kept in mind if they are referenced at some point during the game, as the texts may include references to specific buttons, gestures or commands that must be performed with these controllers. 


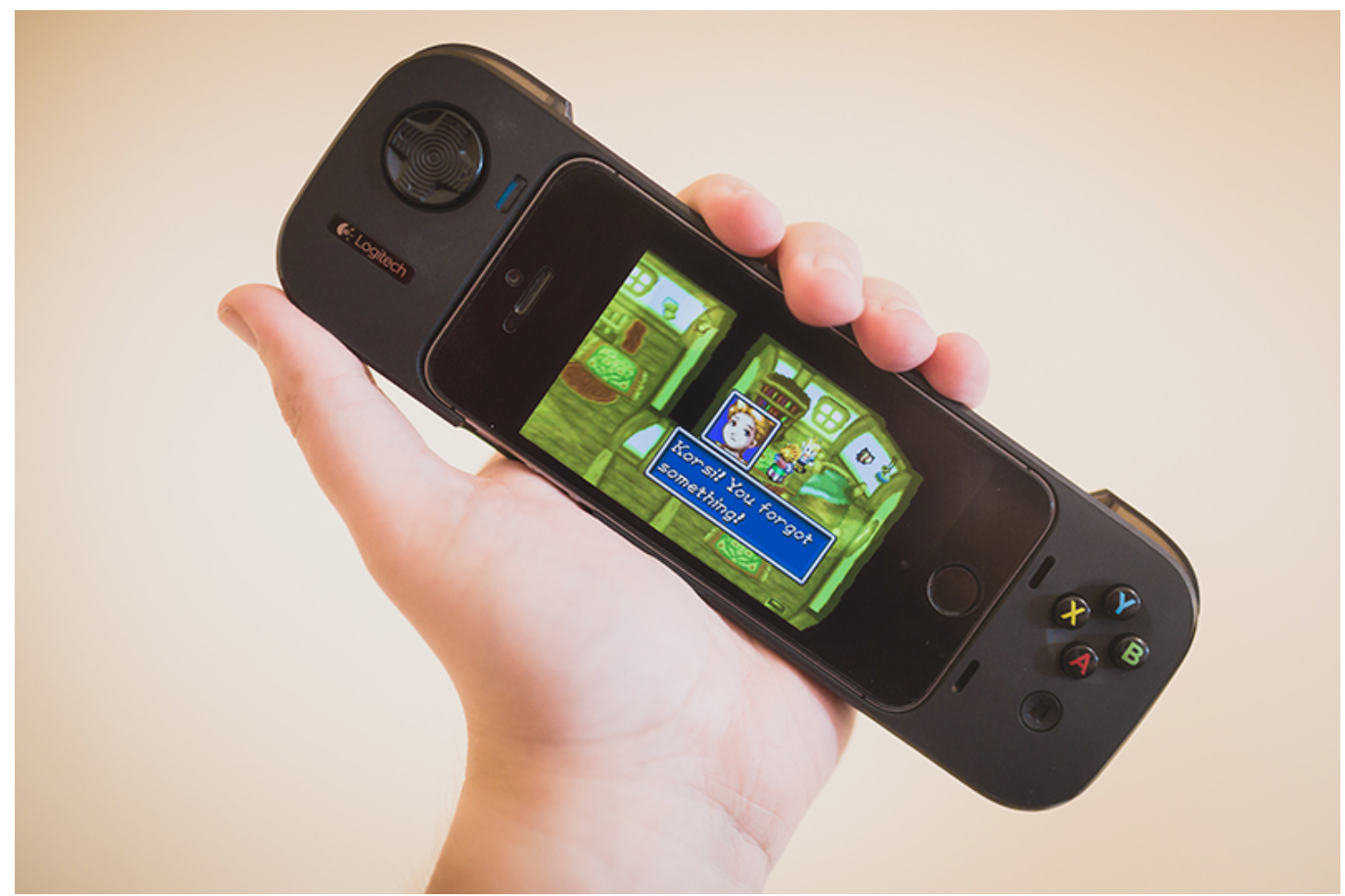

Figure 16. Example of additional controller/pad for smartphone (@ 2016 Logitech)

\subsection{Linguistic testers and error reports}

Unlike the reviewer, the linguistic tester (also known as "beta tester" or "quality control specialist") does not review the text before it is integrated into the video game, but rather after it has been implemented and when the game is already in an advanced development stage, when the first builds of the application can be generated (commonly known as "beta version"). This means that linguistic testers, unlike translators and reviewers, work with the video game itself, which allows them to have all the visual context that translators and reviewers normally lack.

The main purpose of the linguistic tester is to create error reports, errors being known as "bugs" in specialized terminology. These reports are normally generated in different formats. They can be simple Word files or sophisticated Excel sheets, or even done with specialized tools. Bug reports normally include all the information in rows and columns to make verifications in a simple and organized way. Of all the information that can be included in a bug report, Muñoz Sánchez (2013) highlights the following:

- $\quad$ Bug ID

- Date

- Bug reporter

- App/game build number in which the bug was found

- Bug status

- Person in charge of fixing the bug

- Languages affected 
- Category

- Priority/Severity

- Area/Level of the game where the bug was found

- Bug title

- Detailed bug description

- Screenshot or video

- System bug (i.e. only the developers can fix it)

Figure 17 below shows a practical example of a bug report as a table with different types of errors.

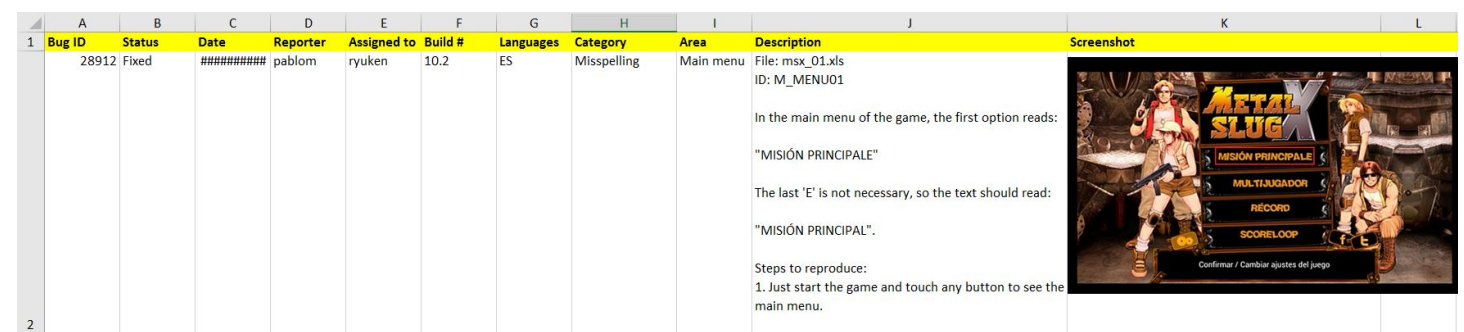

Figure 17. Bug report example

(Picture from Metal Slug X, ( 1999, 2013 SNK/DotEmu)

Errors could be classified following the same parameters as presented in section 4.2, although linguistic testers can also spot problems with the game operation (functional or running errors). In any case, we propose the use of the following bug categories, as they are the most common in the industry:

- Font issues

- Wrong text implementation

- Missing translations/Unlocalized strings

- Typo/Misspelling

- Grammar issues

- Mistranslations

- Overflows/Text overflows

- Truncations/Truncated texts

- Term/Terminology issues

- Inconsistencies

- Instructions/Guidelines issues

- Style/Readability issues

- Subtitle issues

- Audio issues

- Cultural issues 
Lastly, in addition to bug reports, testers-as well as translators and reviewers-work with other documents such as query sheets (to ask questions), change tracker sheets and checklists.

\subsection{Main testing techniques}

Authors such as Levy and Novak (2011) and Schultz, Bryant and Langdell (2010) already included in their main reference works several testing methods that can nowadays be very useful for professionals who must test video games on a mobile device. We will highlight the following techniques as they are especially useful in the localization of mobile device video games.

- Step-by-step testing: It is undoubtedly the most extended method. It basically consists in following, step-by-step, a test plan which includes all the actions and menus of the game in order. The tester must follow this plan strictly, trying not to skip any steps. Test plans can make the tester's job much easier, although it is essential that the plan is comprehensive. If an element is left out of the test plan, the tester might not find it.

- Ad hoc testing: This method complements the prior technique perfectly. An ad hoc testing, proposed by Levy and Novak (2011), consists in testing freely. The tester leaves the test plan and the checklists, and simply plays the game, carrying out the actions that any standard player would. This type of testing can be useful to find problems in locations that were not included in the test plan or to pay attention to details in a similar mindset as the final player.

- Screenshot testing: To avoid sending the game to testers (and even translators) and avoid technical problems, video game and app localization is frequently done by sending screenshots of the implemented text. This accelerates the testing process greatly, as an error report is created mentioning the problems in each screenshot (or even making the changes directly). However, it is only useful if the number of screens is not too elevated, as the developer might take a long time to take all the screenshots in each language (although sometimes the process can be automated).

- Emulation or debug: Although it is not a testing method as such, it is a useful resource in certain situations. The debug is a set of additional options added by the developers to emulate or simulate different actions to test their operation. For example, to simulate a specific currency updating when accessing from a specific country or a variable having a specific behavior. Testers must know and use these options to test the app correctly.

- Normally the tester applies the technique or method required by the client or work team, who are generally in charge of developing the test plan to follow. However, the linguistic tester works with some independence, and therefore must be a disciplined and detail-oriented professional used to working with specific checklists, processes and work flows.

\section{Tools}

In the following section, we present a list of tools that can be used by professionals involved in the process of localizing a mobile video game.

- Traditional video game localization tools: Certainly, the most frequently used tool nowadays in localization is Excel. This is due to its compatibility with file formats frequently used in this field, such as string files in XML and with development tools. However, it is also common to generate file packages to work with computer-aided 
tools such as Trados Studio, memoQ, Wordfast and OmegaT. Other specialized localization tools can also be used, such as SDL Passolo and Alchemy Catalyst.

- Online tools for video game localization: In addition to traditional tools, online tools have been used in recent years. They offer many advantages, among them, the possibility of working on collaboration platforms with the rest of the team members, with the incredible benefits this offers regarding work monitoring, follow-up and project management. Among them, we will mention proprietary tools such as Crowdln, Tethras, Wordbee and ICanLocalize, which are very similar to the traditional video game localization tools, but include the features described above.

- Review and quality control specialized tools: Apart from the CAT tools already mentioned, which include very interesting text editing and review functions, there are specialized tools for this purpose used by reviewers and project managers, such as Xbench and ChangeTracker.

- Specialized testing tools: Testers normally work with tools to generate error reports, such as BugTracker.NET and Bugzilla. They also work with checklists. Currently there are a great number of applications dedicated to creating checklists. We recommend apps such as Todoist, Trello and Wunderlist, that also allow working in collaborative environments.

- Emulators and other useful tools: When testing mobile device apps, it is essential to have the devices for which the apps are intended to carry out a complete and realistic testing. However, when the tester is freelance, they often use OS emulators which are very useful when the original device is not available. Among them, we will highlight emulators such as Bluestacks (Android), iPadian (iOS) and Windows Phone Emulator. The main purpose of these emulators is to install and execute the compiled files of the apps, which are generally in APK (Android), IPA (iOS) and APPX (Windows/Microsoft systems) formats.

The great variety of computer tools that a professional translator specialized in localization must use makes us easily reach the conclusion that translators in this area must deeply develop their computing skills to use all these tools and learn how to use them correctly, especially the most complex ones. Otherwise, these deficits could slow down their work or even affect its quality.

\section{Conclusion}

There is no doubt that video game localization for mobile devices raises all sorts of challenges that bring to light the need to be specialized in localization. With the boom of video games and of independent developers, knowing all the specificities of this practice is essential. Bad scheduling or the lack of knowledge of the complexity of each stage studied in this article can cause delays, a wrong perception of the quality of localization despite having invested in it, or a bad image of the developer because they did not localize their video game. And video game audiences tend to be very demanding. This is not because they do not know the game's original language, but because they believe that localization is essential to enjoy a game to its fullest. In other words, we have luckily reached a point in which localization is a part of the gaming experience, and therefore developers must consider localization as an essential part of the development if they wish to satisfy users of all regions.

Fortunately, nowadays the training in video game localization is more than enough to be prepared for all these challenges, and consequently there are more and more professionals making this industry more mature and implementing good practices to safeguard quality. We believe the present and the future of video game localization for mobile devices is very bright, 
as there is more work, more expert professionals, more teaching, more training, more research and, especially, more passion and dedication to doing things in the best way possible.

\section{References}

Arevalillo Doval, J. J. (2015). A propósito de la norma europea de calidad para los servicios de traducción. <http://cvc.cervantes.es/lengua/esletra/pdf/02/013_arevalillo.pdf >. Page consulted on date: 31.10.2016.

Barceló, C. (2011). "Games localization QA", Multilingual, 122: 36-39.

Bernal-Merino, M. (2015). Translation and Localisation in Video Games: Making Entertainment Software Global. New York/London: Routledge.

Chandler, H. and O'Malley, S. (2011). The Game Localization Handbook (Second edition). Hingham, Massachusetts: Charles River Media, Inc.

D'Angelo, D. (2015). Businesses should learn from Clash of Clans. <https://www.linkedin.com/pulse/businesses-should-learn-from-clash-clans-david-d-angelo>. Page consulted on date: 31.10.2016.

Janner, D. (2013). iPhone App Localization: How To Get 767\% More Downloads By Localizing App Keywords. <http://makeappmag.com/iphone-app-localization-keywords/>. Page consulted on date: 31.10 .2016 .

Levy, L. and Novak, J. (2010): Game Development Essentials: Game QA \& Testing. New York: Delmar Cengage Learning.

Mossop, B. (2014). Revising and Editing for Translators (Third edition). Oxon/New York: Routledge.

Muñoz Sánchez, P. (2016). "Olvídate de las limitaciones de espacio al traducir aplicaciones móviles", Algo más que traducir. <http://algomasquetraducir.com/olvidate-de-laslimitaciones-de-espacio-al-traducir-aplicaciones-moviles/>. Page consulted on date: 31.10.2016.

Muñoz Sánchez, P. (2013). "Testing de videojuegos y software (I): los informes de bugs", Algo más que traducir. <http://algomasquetraducir.com/testing-de-videojuegos-ysoftware-los-informes-de-bugs/>. Page consulted on date: 31.10.2016.

Muñoz Sánchez, P. (2011). "Five reasons to budget more time for testing", Multilingual, 122 : 38.

Muñoz Sánchez, P. (2010). "Métodos para revisar una traducción: ¿cuál es el mejor?", Algo más que traducir. < http://algomasquetraducir.com/metodos-para-revisar-una-traduccioncual-es-el-mejor/>. Page consulted on date: 31.10.2016.

Newzoo (2016). Analysis of Pokémon GO: A Success Two Decades in the Making. $<$ https://newzoo.com/insights/articles/analysis-pokemon-go/>. Page consulted on date: 31.10.2016.

Newzoo (2016). The global games market reaches $\$ 99.6$ billion in 2016 , mobile generating $37 \%$. <https://newzoo.com/insights/articles/global-games-market-reaches-99-6-billion2016-mobile-generating-37/>. Page consulted on date: 31.10.2016.

O'Hagan, M. and Mangiron, C. (2013). Game Localization: Translating for the global digital entertainment industry. Amsterdam/Philadelphia: John Benjamins.

Parra Galiano, S. (2011). La revisión en la norma europea EN-15038 para servicios de traducción. <http://www.entreculturas.uma.es/n3pdf/articul009.pdf>. Page consulted on date: 31.10 .2016 . 
Pearce, H. (2014). The Global Mobile Games Landscape Reloaded (infographic).

<http://www.applift.com/blog/global-mobile-games-landscape-reloaded-infographic.html>. Page consulted on date: 31.10.2016.

Schultz, C., Bryant, R. and Langdell, T. (2011). Game Testing: All in One (Second edition). Dulles/Boston: Mercury Learning \& Information.

Torres Molina, Y. (2007). “Localización de juegos para móvil”, Tradumàtica, 5 <http://ddd.uab.cat/pub/tradumatica/15787559n5/15787559n5a5.pdf>. Page consulted on date: 31.10.2016. 